\section{International Scientific Journal Theoretical \& Applied Science}

\author{
p-ISSN: 2308-4944 (print) e-ISSN: 2409-0085 (online) \\ Year: $2015 \quad$ Issue: $01 \quad$ Volume: 21 \\ Published: $30.01 .2015 \quad$ http://www.T-Science.org
}

Faeq Abdullah AL-Temimei

Faculty of Science, Department of Physics,

University of Kufa, Iraq

Faeqa.jasim@,uokufa.edu.iq

SECTION 10. Astronomy and space research.

\title{
ASTRONOMICAL REFRACTION MODEL BY LEAST SQUARE FITTING ABOVE KUFA ASTRONOMICAL OBSERVATORY
}

\begin{abstract}
In the domains of Astronomy and Geodesy, and according to the different hypotheses dependent on distribution of atmospheric condition, many versions of the computing formulae of Atmospheric refraction have been published, and a lot of versions of Atmospheric refraction tables have also come out to get important and more accurate information. In this study a new mathematical model has been proposed to calculate the Astronomic refraction by using least square fitting method and other mathematical approximations with utilizing data that was collected by the weather link station accompanying Kufa Astronomical Observatory, during the interval 1 15।2011 to 3014|2012. In this model Astronomic refraction in arc sec, when: $P$ in $h P a, T$ in ${ }^{\circ} \mathrm{C}$, and the altitude in deg; also is applicable for altitude range 10 - 300, zenith angle from 600 to 900, in comparison with the previous Astronomic refraction models. Thus, the Astronomic refraction value, in arc sec, is presented at weather conditions $\mathrm{TO}=100 \mathrm{C}, \mathrm{PO}=1005 \mathrm{hpa}$, and zenith angles $600,650,700,750,800,850$ equals to 100.985 , $122.504,154.770,208.515,315.891,637.192$ respectively. The results obtained from the study have been compared with other researchers which was in perfect agreement.

Key words: Astronomical Refraction, Least Square Fitting, Kufa Astronomical Observatory.

Language: English

Citation: AL-Temimei FA (2015) ASTRONOMICAL REFRACTION MODEL BY LEAST SQUARE FITTING ABOVE KUFA ASTRONOMICAL OBSERVATORY. ISJ Theoretical \& Applied Science 01 (21): 107-115. doi: http://dx.doi.org/10.15863/TAS.2015.01.21.18
\end{abstract}

\section{Introduction}

Observational astronomy is the part of Astronomy that deals with research on objects in the sky through scientific observations, where the main source of information about celestial bodies and other objects is the measure of electromagnetic signals. These electromagnetic signals propagate through the atmospheric layers, where they found several phenomena effecting on the light coming from celestial bodies as Astronomic refraction (Kunz et al., 2005; Green, 1985). The real part of the Atmospheric index of refraction is a function of pressure, temperature and density; so, the Atmospheric refraction is the deviation of light from a straight line as it passes through the atmosphere due to the variation of the air refractive index with altitude (Michael E. Thomas and Richard I. Joseph, 1996). Many interesting low-altitude refractive effects are existed because of the atmosphere variations in density and water vapor of partial pressure as a function of position as well as the effect of refraction in the atmosphere shifts the observed position of a star towards the observer's zenith. Therefore, it is a specific effect to a given location.

Recently, the Atmospheric refraction has been a significant subject of studies about its impact on the observations in which there are several hypotheses determine the Astronomic refraction at various wavelength or its theoretical models (Garfinkel, 1967). The simplest precise assumption model of the Atmosphere and the refraction assumes that spherical symmetry of the Earth depends on local weather conditions (Richard J. Mathar, 2004, MAO Wei, Yang Lei and Tie Qiong-xian, 2008).

The effect of the Atmosphere on the propagation of electromagnetic wave signals has been researched by many researchers and some models where the theoretical researches on Astronomical refraction began with the work of B. Tycho, a Danish astronomer, in the end of the $16^{\text {th }}$ century(MAO Wei, Yang Lei and Tie Qiongxian,2008). (Peter D. Noerdlinger,1999) solved the problem of the refraction angle for a spherical atmosphere by a simple, analytic solution, depending only on the surface index of refraction $(\mu)$, the problem of the apparent horizontal displacement of 
the point viewed is also solved analytically, but approximately, because the result depends weakly on an assumed vertical structure of the atmosphere, (Russell D. Sampson, Edward P. Lozowski, and et al., 2003) studied the variability in the Astronomical refraction of the Rising and Setting Sun in Edmonton, Alberta. They found that the seasonal variation of the observed sunset refraction in that study qualitatively matches the predictions of Sugawa, with a maximum occurring in the colder months, (Changbo Wang, Zhangye Wang and Qunsheng Peng,2008) used a new sky light model for atmospheric scattering and refraction where it calculates the refractional track of light through the atmosphere according to the refraction index by adapting a path tracing algorithm considering refraction; the intensity distribution of sky light was calculated, (Krzysztof G. Hełminiak, 2009) studied the impact of the atmospheric differential chromatic refraction on the measurements and precision of relative astrometry. His study has shown that the Atmospheric refraction must be taken into account in Astrometric studies, (S. Cavazzani, S. Ortolani, C.Barbieri, 2011) counted the delay of the arrival times of visible photons on the focal plane of a telescope and its fluctuations as a function of local atmospheric conditions: temperature, pressure, chemical composition and telescope diameter. They also described a theoretical mathematical model for calculating the radius through the study of delay time fluctuations, also (Alejandro Jenkins 2012) described a method to calculate the position of the Sun in the sky as a function of time and the observer's geographic coordinates; his method discussed the Astronomic refraction effect on the position of the sun in the sky.

\section{Astronomic Refraction}

Astronomical refraction addresses ray-bending effects for objects outside the earth's atmosphere in relation to an observer within the atmosphere (Michael E. Thomas and Richard I. Joseph, 1996).
When light was refracted by the atmosphere, the direction of an object differs from the true direction by an amount depending on the atmospheric conditions along the line of sight. This refraction varies with atmosphere density, pressure and temperature, if the object is not too far from the zenith, the atmosphere between the object and the observer can be approximated by a stack of parallel planar layers fig. (2-8), each of which has a certain index of refraction $(\mu \mathrm{i})$ outside the atmosphere $(\mathrm{H}$. Karttunen, P. Kroger, H. Oja, 2006). From Snell's Law of refraction, the index of refraction depends on the density of the air, which further depends on the pressure and temperature. When the altitude angles are over $15^{\circ}$, we can use an approximate formula:

$$
\mathrm{AR}=\frac{\mathrm{P}}{(\mathrm{T}+273.15)} 0.00452 \tan (90-\mathrm{a})
$$

An approximate formula for the Astronomic refraction (for altitude angles from $15^{0}$ to $30^{\circ}$ ) is given by:

$$
\mathrm{AR}=\frac{\mathrm{P}}{(\mathrm{T}+273.15)} \frac{0.1594+0.0196 \mathrm{a}+0.00002 \mathrm{a}^{2}}{1+0.505 \mathrm{a}+0.0845 \mathrm{a}^{2}}
$$

Where: (a) is altitude angle in degrees, (T) is Temperature in Celsius degree, (P)pressure in millibars and (AR) is Astronomic refraction.

\section{A New Model of Astronomic Refraction}

In the present work, a new model has been proposed by adopting least square fitting of Astronomical refraction in terms of atmospheric parameters measured by the weather link station of Kufa observatory which is located $(35 \mathrm{~m})$ altitude above sea level with geodetic coordinates (longitude 320.0 and latitude 44.50).

For least square fitting to function in this state, it is used (n) as the degree of the polynomial and (N) is the number of the data.it can be assumed the functional relationship (F.Curtis and O.Patrick, 1989; Angus M. Brown, 2001; K. Madsen, H.B. Nielsen, O. Tingleff, 2004; Mehmet Sari, 2012):

$$
y=c_{0}+c_{1} x+c_{2} x^{2}+\cdots+c_{n} x^{n}
$$

With errors defined by :

$$
e_{i}=Y_{i}-y_{i}=Y_{i}-c_{0}-c_{1} x_{i}-c_{2} x_{i}^{2}-\cdots-c_{n} x_{i}^{n}
$$

Where: $Y_{i}$ represents the observed or experimental value corresponding to $x_{i}$, with $x_{i}$ free error.

$$
S=\sum_{i=1}^{N} e_{i}^{2}=\sum_{i=1}^{N}\left(Y_{i}-c_{0}-c_{1} x_{i}-c_{2} x_{i}^{2}-\cdots-c_{n} x_{i}^{n}\right)^{2}
$$

The optimum values of refraction can be obtained by setting, all the partial derivatives $\left(\partial S / \partial c_{0}, \partial S / \partial c_{1}, \ldots, \partial S / \partial c_{n}\right)$ to zero:

$$
\begin{aligned}
& \frac{\partial S}{\partial c_{0}}=0=\sum_{i=1}^{N} 2\left(Y_{i}-c_{0}-c_{1} x_{i}-c_{2} x_{i}^{2}-\cdots-c_{n} x_{i}^{n}\right)(-1) \\
& \frac{\partial S}{\partial c_{1}}=0=\sum_{i=1}^{N} 2\left(Y_{i}-c_{0}-c_{1} x_{i}-c_{2} x_{i}^{2}-\cdots-c_{n} x_{i}^{n}\right)\left(-x_{i}\right) \\
& \frac{\partial S}{\partial c_{n}}=0=\sum_{i=1}^{N} 2\left(Y_{i}-c_{0}-c_{1} x_{i}-c_{2} x_{i}^{2}-\cdots-c_{n} x_{i}^{n}\right)\left(-x_{i}^{n}\right)
\end{aligned}
$$

writing the equations for these given $(n+1)$ equations: 
Dividing each by (-2) and rearranging gives the

$(\mathrm{n}+1)$ normal equations to be solved simultaneously:

$$
\begin{gathered}
c_{0} N+c_{1} \sum x_{i}+c_{2} \sum x_{i}^{2}+\cdots+c_{n} \sum x_{i}^{n}=\sum Y_{i}, \\
c_{0} \sum x_{i}+c_{1} \sum x_{i}{ }^{2}+c_{2} \sum x_{i}{ }^{3} \ldots+c_{n} \sum x_{i}{ }^{n+1}=\sum x_{i} Y_{i}, \\
c_{0} \sum x_{i}{ }^{2}+c_{1} \sum x_{i}{ }^{3}+c_{2} \sum x_{i}{ }^{4} \ldots+c_{n} \sum x_{i}{ }^{n+2}=\sum x_{i}{ }^{2} Y_{i}, \\
c_{0} \sum x_{i}^{n}+c_{1} \sum x_{i}{ }^{n+1}+c_{2} \sum x_{i}{ }^{n+2} \ldots+c_{n} \sum x_{i}{ }^{2 n}=\sum x_{i}{ }^{n} Y_{i},
\end{gathered}
$$

Putting these equations in matrix form shows an interesting way in the coefficient matrix:

$$
\left[\begin{array}{cccccc}
N & \sum x_{i} & \sum x_{i}{ }^{2} & \sum x_{i}{ }^{3} & \ldots & \sum x_{i}{ }^{n 2} \\
\sum x_{i} & \sum x_{i}{ }^{2} & \sum x_{i}{ }^{3} & \sum x_{i}{ }^{4} & \ldots & \sum x_{i}{ }^{n+1} \\
\sum x_{i}{ }^{2} & \sum x_{i}{ }^{3} & \sum x_{i}{ }^{4} & \sum x_{i}{ }^{5} & \ldots & \sum x_{i}{ }^{n+2} \\
\sum x_{i}{ }^{n} & \sum x_{i}{ }^{n+1} & \sum x_{i}{ }^{n+2} & \sum x_{i}{ }^{n+3} & \ldots & \sum x_{i}{ }^{2 n}
\end{array}\right] c=\left[\begin{array}{c}
\sum Y_{i} \\
\sum x_{i} Y_{i} \\
\sum x_{i}{ }^{2} Y_{i} \\
\sum x_{i}{ }^{n} Y_{i}
\end{array}\right]
$$

All the summations in equations (9) and (10) run from 1 to $\mathrm{N}$. and the matrix of equation (10) is called the normal matrix for least -squares fitting (F.Curtis and O.Patrick, 1989).
By using this method for equation (1) of Astronomic refraction model and by using data from Weather link station of the Kufa Astronomic Observatory, see Appendix (C), The following expression is obtained :

$$
A R=\frac{P}{T+273.15}\left(-1.8706+\frac{901.3392}{a}-\frac{21.9383}{a^{2}}+\frac{12.6801}{a^{3}}\right)
$$

This equation represents a new model for Astronomic refraction, which is quite different from previous models by the following:

1- Astronomic refraction in ( $\operatorname{arcsec})$, where: $\mathrm{P}$ in $(\mathrm{hPa}), \mathrm{T}$ in $\left({ }^{0} \mathrm{C}\right)$, and the altitude a in (deg).

2- Equation (11) is applicable for altitude range $1^{0}$ - $30^{\circ}$ (zenith angle from $60^{\circ}$ to $90^{\circ}$ ) in comparison with the previous Astronomic refraction models(H. Karttunen ,P. Kroger ,H. Oja, 2006).

\section{Data Analysis}

The following tables and figures are the statistical analysis for the atmospheric parameters " temperature (in ${ }^{0} \mathrm{C}$ ) and pressure (in hpa)" are measured by the Weather link station at Kufa Astronomical Observatory "altitude 35 above sea level, longitude $32^{0} .0$ and latitude $44.5^{0}$ " during the interval $1 \backslash 5 \backslash 2011$ to $30 \backslash 4 \backslash 2012$.

Table (1) represented the statistical analysis for the temperature (in ${ }^{0} \mathrm{C}$ ) measured by the Weather link station at Kufa Astronomical Observatory during the interval $1 \backslash 5 \backslash 2011$ to $30 \backslash 4 \backslash 2012$ from two o'clock to five o'clock in the morning. The average of minimum and maximum temperatures have been taken in this period. It can be seen from these results that maximum value of temperature at August $2011\left(40.833{ }^{\circ} \mathrm{C}\right)$ and the minimum value of temperature at January $2012\left(3.558{ }^{\circ} \mathrm{C}\right)$. Also it can be seen from the results in table (1-1) the highest amount of variance in temperature at March 2012(17.500 $\left.{ }^{0} \mathrm{C}^{2}\right)$ and the less amount at July $2011\left(3.351{ }^{0} \mathrm{C}^{2}\right)$. And from this statistical table the highest amount of mean in temperature at July 2011(36.897 $\left.{ }^{\circ} \mathrm{C}\right)$ and the less amount at December $2011\left(4.278^{\circ} \mathrm{C}\right)$.

Table 1

The statistical analysis for the temperature measured by the Weather link station at Kufa Astronomical Observatory during the interval $1 \backslash 5 \backslash 2011$ to $30 \backslash 4 \backslash 2012$.

\begin{tabular}{lllll}
\hline Month & $\begin{array}{l}\text { Mean } \\
\left.\text { (in }{ }^{\mathbf{0}} \mathbf{C}\right)\end{array}$ & $\begin{array}{l}\text { Variance } \\
\left(\text { in }^{\mathbf{0}} \mathbf{C}^{\mathbf{2}}\right.\end{array}$ & $\begin{array}{l}\text { Max. value } \\
\left.\text { (in }{ }^{\mathbf{0}} \mathbf{C}\right)\end{array}$ & $\begin{array}{l}\text { Min. value } \\
\left.\text { (in }{ }^{\mathbf{0}} \mathbf{C}\right)\end{array}$ \\
\hline May 2011 & 29.421 & 11.118 & 36.558 & 20.800 \\
June 2011 & 34.861 & 4.157 & 37.863 & 30.663 \\
July 2011 & 36.897 & 3.351 & 40.238 & 32.783 \\
Aug. 2011 & 36.197 & 3.465 & 40.833 & 33.346 \\
Sept. 2011 & 31.813 & 13.984 & 40.400 & 26.700 \\
Octo. 2011 & 24.155 & 9.160 & 28.421 & 18.379
\end{tabular}


Nove. 2011

Dece. 2011

Janu. 2012

Febr. 2012

March 2012

April 2012
14.388

10.048

11.212

12.923

17.345

27.218
10.059

4.278

7.068

6.956

17.500

8.814
20.333

14.929

15.358

17.592

23.688

32.692
7.521

7.233

3.558

8.288

10.067
The following figure (1) describes the standard deviation of temperature measured by the Weather link station at Kufa Astronomical Observatory during the interval $1 \backslash 5 \backslash 2011$ to $30 \backslash 4 \backslash 2012$. It can be seen from these results that the highest amount of standard deviation of temperature at March $2012\left(4.183{ }^{\circ} \mathrm{C}\right)$ and the less amount standard deviation at July $2011\left(1.83^{\circ} \mathrm{C}\right)$.

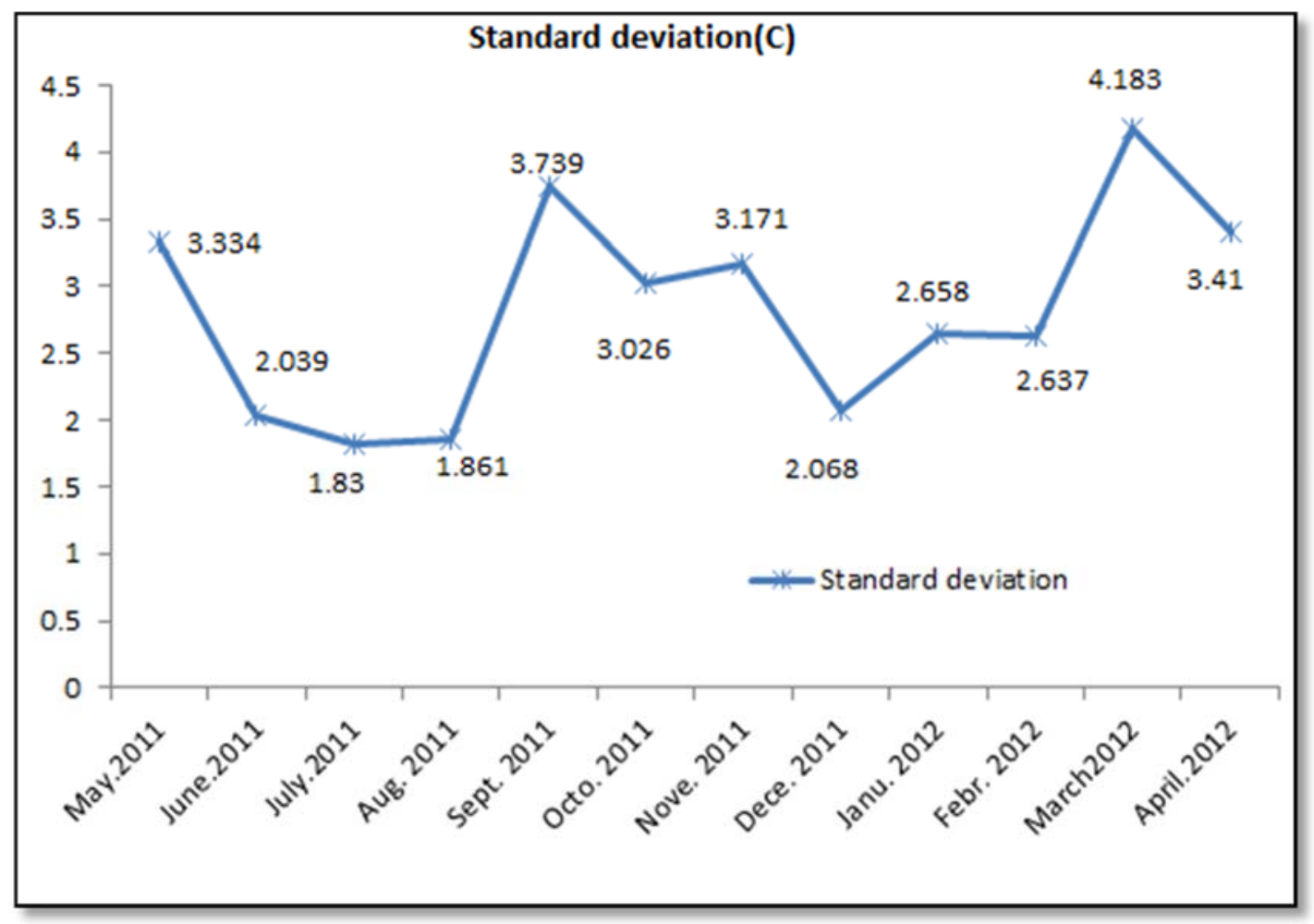

Figure 1 - The standard deviation of temperature at Kufa Astronomical Observatory during the interval $1 \backslash$ $5 \backslash 2011$ to $30 \backslash 4 \backslash 2012$.

Table (2) represented the statistical analysis for the pressure (in hpa) measured by the Weather link station at Kufa Astronomical Observatory during the interval $1 \backslash 5 \backslash 2011$ to $30 \backslash 4 \backslash 2012$ from two o'clock to five o'clock in the morning where the average of pressure in this period was evaluated. It can be seen from these results that the maximum value of pressure at February 2012 (1029.60 hpa) and the minimum value of pressure at August 2011
(994.4 hpa) . Also it can be seen from the results in table (3-2) that the highest amount of variance in pressure at February $2012\left(45.533(\mathrm{hpa})^{2}\right)$ and the less amount at September $2011\left(5.063(\mathrm{hpa})^{2}\right)$. And it can be seen from this statistical table the highest amount of mean in pressure at December 2011(1021.4 hpa) and the less amount at July 2011(998 hpa). 
Table 2

The statistical analysis for the pressure measured by the Weather link station at Kufa Astronomical Observatory during the interval $1 \backslash 5 \backslash 2011$ to $30 \backslash 4 \backslash 2012$

\begin{tabular}{lllll}
\hline Month & $\begin{array}{c}\text { Mean } \\
(\mathrm{hpa})\end{array}$ & $\begin{array}{l}\text { Variance } \\
(\mathrm{hpa})^{2}\end{array}$ & $\begin{array}{c}\text { Max. value } \\
\text { (hpa) }\end{array}$ & $\begin{array}{l}\text { Min. value } \\
\text { (hpa) }\end{array}$ \\
\hline May 2011 & 1007.3 & 6.147 & 1012.67 & 1001.01 \\
June 2011 & 1000.7 & 12.452 & 1008.40 & 995.33 \\
July 2011 & 998.0 & 5.679 & 1003.07 & 994.93 \\
Aug. 2011 & 998.1 & 5.955 & 1001.87 & 994.4 \\
Sept. 2011 & 1003.1 & 5.063 & 1010.8 & 999.73 \\
Octo. 2011 & 1011.6 & 5.210 & 1016.0 & 1005.73 \\
Nove. 2011 & 1016.6 & 8.889 & 1022.13 & 1010.27 \\
Dece. 2011 & 1021.4 & 10.936 & 1026.4 & 1013.07 \\
Janu. 2012 & 1018.7 & 8.644 & 1025.33 & 1012.67 \\
Febr. 2012 & 1017.6 & 45.533 & 1029.60 & 1006.27 \\
March 2012 & 1017.4 & 40.856 & 1029.35 & 1005.60 \\
April 2012 & 1010.9 & 10.507 & 1017.33 & 1005.07 \\
\hline
\end{tabular}

The following figure (2) describes the standard deviation of pressure measured by the Weather link station at Kufa Astronomical Observatory during the interval $1 \backslash 5 \backslash 2011$ to $30 \backslash 4 \backslash 2012$. It can be seen from these results that the highest amount of standard deviation of pressure at February 2012(6.747 hpa) and the less amount standard deviation at September 2011(2.25 hpa).

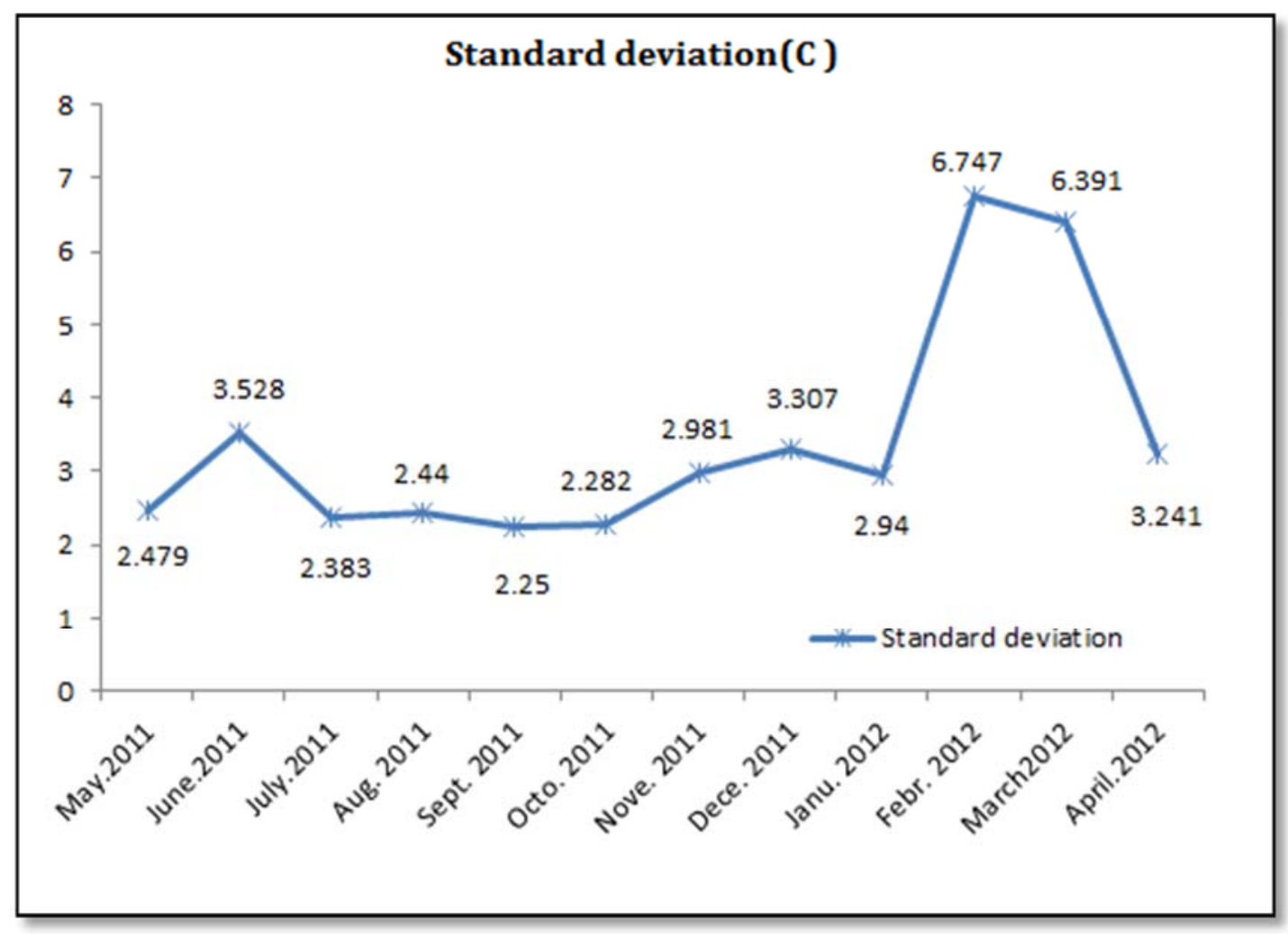

Figure 2 - The standard deviation of pressure at Kufa Astronomical Observatory during the interval $1 \backslash 5 \backslash$ 2011 to $30 \backslash 4 \backslash 2012$. 


\section{5- Results and Discussion}

In the Astronomic refraction model, the Astronomic refraction has been estimated by using two equations(1), and (2) for altitude angles from $\left(0^{0}-30^{0}\right)$ (H. Karttunen ,P. Kroger ,H. Oja, 2006). While in the new model, the Astronomic refraction has been accounted for altitude angles from $\left(0^{0}-30^{0}\right)$ by using the final equation (11) that was obtained from this model directly with units (in arc sec). Without the need to transfer or change the units of temperature $\left(\right.$ in $\left.^{0} \mathrm{C}\right)$, altitude angle(in deg) and pressure (in hpa ), these changes are included within the derivation of this new model.

The table (3) refers to the value of the Astronomical refraction by using the new model for the interval $(1 \backslash 5 \backslash 2011$ to $30 \backslash 4 \backslash 2012)$ from two o'clock to five o'clock in the morning. The average of minimum and maximum temperatures have been taken as well as the average of pressure in this period. It can be seen from this table the value of Astronomic refraction depending on temperature and pressure with altitude angle and the correlation factor of $(\mathrm{AR}, \mathrm{T})$ and $(\mathrm{AR}, \mathrm{P})$ at each altitude angle.

The Astronomic refraction during the interval $1 \backslash 5 \backslash 2011$ to $30 \backslash 4 \backslash 2012$ according to the new model

Table 3

\begin{tabular}{|c|c|c|c|c|c|c|c|c|}
\hline Date & $\begin{array}{l}\text { P } \\
\text { (hpa) }\end{array}$ & $\begin{array}{l}\mathrm{T} \\
\left({ }^{0} \mathrm{C}\right)\end{array}$ & $\begin{array}{l}\mathrm{AR} \\
(\operatorname{arc~sec}) \\
\mathrm{a}=5^{0} \\
\mathrm{z}=85^{0}\end{array}$ & $\begin{array}{l}\text { AR } \\
(\operatorname{arcsec}) \\
a=10^{0} \\
z=80^{0}\end{array}$ & $\begin{array}{l}\text { AR } \\
(\operatorname{arcsec}) \\
a=15^{0} \\
z=75^{0}\end{array}$ & $\begin{array}{l}\text { AR } \\
(\operatorname{arcsec}) \\
a=20^{0} \\
z=70^{0}\end{array}$ & $\begin{array}{l}\text { AR } \\
(\operatorname{arcsec}) \\
a=25^{0} \\
z=65^{0}\end{array}$ & $\begin{array}{l}\text { AR } \\
(\operatorname{arc~sec}) \\
a=30^{\circ} \\
z=60^{\circ}\end{array}$ \\
\hline $15 / 5 / 2011$ & $\begin{array}{l}1007.73 \\
\pm 1.848\end{array}$ & $\begin{array}{l}25.508 \\
\pm 2.748\end{array}$ & 599.344 & 297.128 & 196.130 & 145.577 & 115.227 & 94.986 \\
\hline 15/6/2011 & $\begin{array}{l}1006.93 \\
\pm 3.747\end{array}$ & $\begin{array}{l}30.663 \\
\pm 1.843\end{array}$ & 588.697 & 291.849 & 192.645 & 142.991 & 113.180 & 93.299 \\
\hline $15 / 7 / 2011$ & $\begin{array}{l}998.00 \\
\pm 2.431\end{array}$ & $\begin{array}{l}39.842 \\
\pm 1.311\end{array}$ & 566.362 & 280.777 & 185.337 & 137.566 & 108.886 & 89.759 \\
\hline $15 / 8 / 2011$ & $\begin{array}{l}1001.87 \\
\pm 1.000\end{array}$ & $\begin{array}{l}34.338 \\
\pm 1.043\end{array}$ & 578.747 & 286.917 & 189.390 & 140.574 & 111.267 & 91.722 \\
\hline $15 / 9 / 2011$ & $\begin{array}{l}1002.53 \\
\pm 2.716\end{array}$ & $\begin{array}{l}29.70 \\
\pm 3.926\end{array}$ & 587.982 & 291.495 & 192.412 & 142.817 & 113.043 & 93.185 \\
\hline $15 / 10 / 2011$ & $\begin{array}{l}1014.40 \\
\pm 2.376\end{array}$ & $\begin{array}{l}26.396 \\
\pm 3.045\end{array}$ & 601.518 & 298.206 & 196.841 & 146.105 & 115.645 & 95.331 \\
\hline $15 / 11 / 2011$ & $\begin{array}{l}1015.47 \\
\pm 3.160\end{array}$ & $\begin{array}{l}13.767 \\
\pm 3.193\end{array}$ & 628.660 & 311.661 & 205.723 & 152.697 & 120.863 & 99.632 \\
\hline $15 / 12 / 2011$ & $\begin{array}{l}1023.33 \\
\pm 3.822\end{array}$ & $\begin{array}{l}10.108 \\
\pm 1.711\end{array}$ & 641.712 & 320.132 & 209.994 & 155.868 & 123.372 & 101.701 \\
\hline $15 / 01 / 2012$ & $\begin{array}{l}1020.67 \\
\pm 2.679\end{array}$ & $\begin{array}{l}10.279 \\
\pm 3.137\end{array}$ & 639.660 & 317.115 & 209.323 & 155.369 & 122.978 & 101.376 \\
\hline $15 / 02 / 2012$ & $\begin{array}{l}1018.67 \\
\pm 6.808\end{array}$ & $\begin{array}{l}16.958 \\
\pm 3.096\end{array}$ & 623.706 & 309.205 & 204.102 & 151.494 & 119.911 & 98.847 \\
\hline $15 / 03 / 2012$ & $\begin{array}{l}1010.27 \\
\pm 6.488\end{array}$ & $\begin{array}{l}22.879 \\
\pm 4.009\end{array}$ & 606.193 & 300.523 & 198.371 & 147.240 & 116.544 & 96.072 \\
\hline $15 / 04 / 2012$ & $\begin{array}{l}1008.00 \\
\pm 1.826\end{array}$ & $\begin{array}{l}24.025 \\
\pm 2.811\end{array}$ & 602.490 & 298.687 & 197.159 & 146.341 & 115.832 & 95.485 \\
\hline
\end{tabular}

The following fig. (3) illustrates the changes of the Astronomic refraction above Kufa Astronomical Observatory with altitude angles from $\left(0^{0}-30^{0}\right)$ during weather conditions through above mentioned period. It can be seen from this figure that there is a gradual exponential decrease in the Atmospheric refraction with an increase in the altitude angles. 


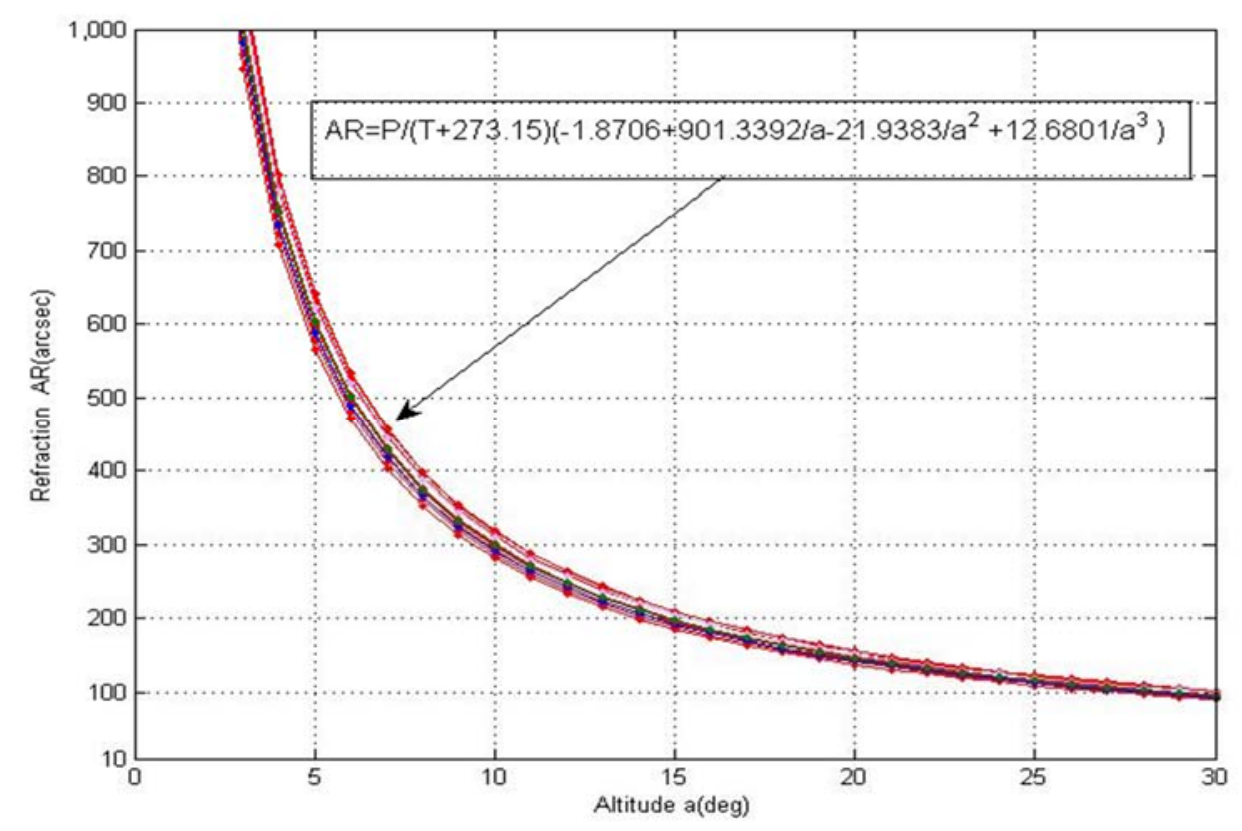

Figure 3 - Astronomic refraction at different altitude angles according to the new model.

Table(4) indicates the extent of the correspondence of the results that are obtained according to the new model and Astronomic refraction model under the same weather conditions, that the result calculated in this present model is very close to that of Astronomic refraction model ( $\mathrm{H}$. Karttunen, P. Kroger, H. Oja, 2006).

Table 4

Comparing Astronomic refraction by using the new model with Astronomic refraction model.

\begin{tabular}{|c|c|c|c|c|c|c|}
\hline $\begin{array}{c}\mathrm{Z} \\
\text { Deg }\end{array}$ & $\begin{array}{c}\text { New model } \\
\mathrm{P}=1015.47 \mathrm{hpaT}=13.76\left({ }^{\circ} \mathrm{C}\right)\end{array}$ & $\begin{array}{c}\text { Astronomic } \\
\text { refraction } \\
\text { model } \\
\mathrm{P}=1015.47 \mathrm{hpa} \\
\mathrm{T}=13.76{ }^{\circ} \mathrm{C}\end{array}$ & 离 & $\begin{array}{c}\text { New model } \\
\mathrm{P}=1007.73 \mathrm{hpa} \\
\mathrm{T}=25.50^{\circ} \mathrm{C}\end{array}$ & $\begin{array}{c}\text { Astronomic } \\
\text { refraction model } \\
\mathrm{P}=1007.73 \mathrm{hpa} \\
\mathrm{T}=25.50^{\circ} \mathrm{C}\end{array}$ & E \\
\hline 60 & 99.632 & 101.007 & -1.375 & 94.986 & 96.297 & -1.311 \\
\hline 65 & 120.863 & 121.220 & -0.357 & 115.227 & 115.567 & -0.34 \\
\hline 70 & 152.697 & 151.590 & 1.107 & 145.577 & 144.521 & 1.056 \\
\hline 75 & 205.723 & 205.249 & 0.474 & 196.130 & 195.678 & 0.452 \\
\hline 80 & 311.661 & 311.900 & -0.239 & 297.128 & 297.355 & -0.227 \\
\hline 85 & 628.660 & 628.611 & 0.049 & 599.344 & 599.297 & 0.047 \\
\hline
\end{tabular}

Here is a comparison between the results with other works under various conditions as they are shown in the following table (5). It can be seen from table (5) that the result calculated in this present model is very close to that in model (Peter D. Noerdlinger ,1999), model (Laweence H. Auer and E. Myles Standish, 2000) and model (Minodora Lipcanu, 2005) . 
Comparison of Astronomic refraction in the new model with other models

Table 5

\begin{tabular}{cllll}
\hline Z(deg) & New model for data at 15/12/2011 & Ref. [1999] & Ref. [2000] & Ref. [2005] \\
\hline 60 & 101.701 & 99.057 & 103.99 & 98.47 \\
65 & 123.372 & 122.789 & $\ldots \ldots$ & $\ldots \ldots$ \\
70 & 155.868 & 157.184 & $\ldots \ldots$. & 155.38 \\
75 & 209.994 & 213.248 & 221.34 & $\ldots \ldots$ \\
80 & 320.132 & 322.96 & 329.46 & 312.33 \\
85 & 641.712 & 642.152 & 588.87 & 577.89 \\
\hline
\end{tabular}

The results observed in the table above are compatible with the compared references, with some differences in the values which belong to the difference in weather conditions and the number of variables used in addition to the type of computation method that was used.

6-Conclusions The tables of refraction used in Astronomy and Navigation are generally based on constitution of the atmosphere. This was unavoidable at a time when the meteorological data available conditions have become ripe for a new approach to problem. Many models derived for this phenomena where the effect of Astronomic refraction in the atmosphere shifts the observed position of a star towards the observer's zenith; therefore, this effect can be considered in specifying the real position to the celestial body. Due to the refraction theory, the ray path through the atmosphere is curved. We can calculate the refraction index in every altitude, and then gain the ray path by the Snell's law. The study of Astronomic refraction for the first layer (troposphere) is very significant as this layer is more effective on propagating light from celestial body. Also The path banding correction of refraction should be taken into account specially when zenith distance is large. Through the results of the study found the Astronomic refraction is inversely proportional to temperature and altitude, but directly proportional to pressure. The outcomes of this study showed that better results are obtained than the previous models and the new model. The future work such a study can be carried out on the measurement of extinction coefficient also measurement of aerosols of the atmosphere using lidar system.

\section{References:}

1. Alejandro Jenkins (2012) "The sun's position in the sky", arXiv:1208.1043v2 [physics.pop-ph] $12 \operatorname{Nov}(2012)$.

2. Angus M. Brown (2001) "A step-by-step guide to non-linear regression analysis of experimental data using a Microsoft Excel spreadsheet”, Computer Methods and Programs in Biomedicine 65, pp.191-200.

3. B. Garfinkel (1967) "Astronomic Refraction in Polytropic Atmosphere", Journal of The Astronomical , No. 2, Vol.72.

4. Changbo Wang, Zhangye Wang and Qunsheng Peng (2007) " Real-time rendering of sky scene considering scattering and refraction" COMPUTER ANIMATION AND VIRTUAL WORLDS Comp. Anim. Virtual Worlds; 18: pp.539-548, Published online inWiley InterScience.

5. F.Curtis and O.Patrick (1989) "Applied Numerical Analysis", California Polytechnic State University San Luis Obispo, Fourth ed.
6. Green RM (1985) Spherical Astronomy (Cambridge, London: Cambridge University Press).

7. H. Karttunen, P. Kroger, H. Oja, M. Poutanen, K.J. Donner (2006) "Fundamental Astronomy", ISBN 978-3-540-00179-9 4th Edition, Springer-Verlag Berlin Heidelberg New York.

8. H. Lawence and E.Myes (2000) "Astronomical Refraction: Computational Method for all Zenith angles" , J. The Astronomical, No.119,PP.2472-2474.

9. K. Madsen, H.B. Nielsen, O. Tingleff (2004)" METHODS FOR NON-LINEAR LEAST SQUARES PROBLEMS", Informatics and Mathematical Modelling Technical University of Denmark2nd Edition, April 2004.

10. Krzysztof G. Hełminiak (2009) 'Impact of the atmospheric refraction on the precise astrometry with adaptive optics in infrared", New Astronomy 14, pp.521-527.

11. Kunz G, Heemskerk E, van Eijk L (2005) SPIE $5981,84$. 
12. L Minodora (2005) "A direct method for the calculation of Astronomical Refraction", J. Proceedings of the Romanian, Series A, Vol. 6, No. 2.

13. MAO Wei, Yang Lei and Tie Qiong-xian (2008) "On Astronomical Atmospheric Refraction" Chinese Astronomy and Astrophysics, 32, pp. 439-448.

14. MAO Wei, Yang Lei and Tie Qiong-xian (2008) "Path Bending Correction for Refraction Delay of Electromagnetic Waves ",Chinese Astronomy and Astrophysics 32 pp.335-341.

15. Michael E. Thomas and Richard I. Joseph (1996) "Astronomical Refraction", JOHNS HOPKINS APL TECHNICAL DIGEST, VOLUME 17, NUMBER 3.

16. Peter D. Noerdlinger (1999) "Atmospheric refraction effects in Earth remote sensing",
ISPRS Journal of Photogrammetry \& Remote Sensing 54, pp.360-373.

17. Richard J. Mathar (2004) " Atmospheric Refraction Path Integrals in Ground-Based Interferometry" arXiv:astro-ph/0411384v1 14 Nov 2004.

18. Russell D. Sampson, Edward P. Lozowski, and et al. (2003) "Variability in the Astronomical Refraction of the Rising and Setting Sun", Publications of the Astronomical Society of the Pacific, 115:1256-1261, 2003 October_ 2003. The Astronomical Society of the Pacific. All rights reserved. Printed in U.S.A.

19. S. Cavazzani, S. Ortolani, C.Barbieri (2011) "Fluctuations of Photon Arrival Times in Free Atmosphere", arXiv:1112.3499v1 [astro-ph.IM] 15 Dec 2011. 